ISSN e-2448-4849

región y sociedad / año 33 / 2021 / e1403

https://doi.org/10.22198/rys2021/33/1403

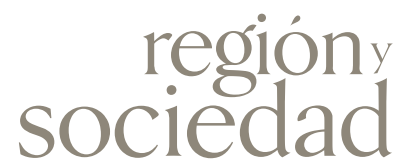

\title{
Migración de retorno y reinserción en la zona metropolitana de Monterrey
}

\author{
Return Migration and Reintegration \\ in the Monterrey Metropolitan Area
}

\author{
María del Socorro Arzaluz Solano* (D) https://orcid.org/0000-0002-3216-0813 \\ Gabriela Zamora Carmona** (iD https://orcid.org/0000-0001-9798-1973
}

\section{Resumen}

Objetivo: observar los efectos de las políticas federales que implementa el gobierno de Nuevo León para atender a la población que retorna de Estados Unidos. Metodología: entrevistas a los actores gubernamentales y a los no gubernamentales. Se formó un grupo de foco con migrantes que retornaron. Resultados: en Nuevo León la migración de retorno no es tema prioritario en la agenda de gobierno: las acciones en materia de empleo, capacitación y salud son insuficientes para las necesidades de esa población. Limitación: el poco acceso a las personas que retornan porque faltan registros. Valor: I) el análisis del funcionamiento local del Fondo de Apoyo a Migrantes, 2) la ubicación de la zona metropolitana de Monterrey como el eje más importante de flujos migratorios en el noreste y 3) las propuestas de política pública para la atención a migrantes de retorno. Conclusiones: a diferencia de otras entidades, en Nuevo León no se percibe la migración como un problema público y, en consecuencia, no hay una política migratoria ni una instancia especializada para atender a la población que retorna, lo cual afecta el proceso de reinserción.

Palabras clave: migración de retorno; deportación; política pública; Nuevo León; noreste de México.

\begin{abstract}
Objective: to observe the effects of the federal policies implemented by the state government in Nuevo León for the population that has returned from the United States. Methodology: interviews to governmental and non-governmental actors. A focus group with returning migrants was made. Results: in Nuevo León, returning migration is not a priority issue on the government's agenda and actions in the areas of employment, training and health are insufficient for the needs of the population. Limitation: limited access to returnees due to lack of registration. Value: I) the analysis of the local functioning of the Migrant Support Fund; 2) the location of the metropolitan area of Monterrey as the most important axis of migratory flows in the Northeast, and 3) public care policy proposals for returning migrants. Conclusions: unlike other entities, Nuevo León lacks of the perception that returning migration is a public problem; in consequence, there is no migration policy or a specialized body for the attention to the migrant population, which affects their reintegration process.

Keywords: return migration; deportation; public policy; Nuevo León; Northeast Mexico.
\end{abstract}

Cómo citar:Arzaluz Solano, M. S., y Zamora Carmona, G. (2021). Migración de retorno y reinserción en la zona metropolitana de Monterrey. región y sociedad, el403. doi: I0.22 I98/rys202 I/33/I403

*Autora para correspondencia. El Colegio de la Frontera Norte, Departamento de Estudios de Administración Pública. Técnicos Núm. 277, colonia Tecnológico, C. P. 64700. Monterrey, Nuevo León, México. Correo electrónico: sarzaluz@colef.mx

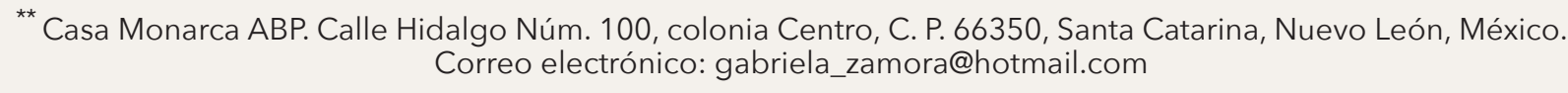

Recibido: 1 de octubre de 2020

Reevaluado: 7 de mayo de 2021

Aceptado: 16 de junio de 2021

Liberado: 11 de agosto de 2021

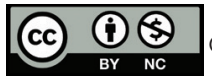

Esta obra está protegida bajo una Licencia Creative Commons Atribución-No Comercial 4.0 Internacional. 


\section{Introducción}

El artículo forma parte de una investigación más amplia realizada en varias entidades de México: Baja California, Sonora, Chihuahua, Nuevo León, Tamaulipas, Guanajuato, Michoacán, Estado de México y Puebla. El proyecto Políticas Multinivel para el Retorno y la (Re)inserción de Migrantes Mexicanos y sus Familiares tiene como objetivo formular una propuesta de política pública multinivel de largo alcance que contribuya a reducir la vulnerabilidad y facilite el retorno o reinserción social y económica de la población migrante de origen mexicano que regresa al país procedente de Estados Unidos. Dicho estudio comprende tres partes: 1) el análisis demográfico de las implicaciones del retorno a México; 2) el examen de los marcos normativo, jurídico y legal que amparan el retorno y la reinserción de los mexicanos; 3) el estudio empírico de las prácticas y de las políticas de las diversas entidades de México. El análisis que se desarrolla en este documento es del caso de Nuevo León y forma parte de la tercera sección del proyecto mencionado. ${ }^{1}$

Los objetivos en el caso de Nuevo León son 1) identificar a los actores gubernamentales que intervienen en el proceso de política pública de atención a los migrantes en la entidad y determinar cuáles son las organizaciones de la sociedad civil que prestan apoyo a esa población; 2) observar los efectos de las políticas federales de atención diseñadas para la población de retorno y que el gobierno estatal de Nuevo León implementa, sobre todo en cuestiones de empleo, educación y salud.

El artículo tiene la siguiente estructura: en la primera parte se presenta la discusión conceptual sobre los temas de migración de retorno y de política pública. Enseguida, se revisa el estado del arte del tema del retorno a México. Después se presentan datos que indican la relevancia de esta población en el país. En la segunda parte se analiza el contexto estatal y urbano de Nuevo León y se describe de forma sucinta la política en materia de migración que tiene esa entidad. Le sigue la descripción de los programas gubernamentales que funcionaban hasta 2018 para la población que retorna. Ésta se divide en dos momentos: 1) el proceso en la frontera (estrategia Somos Mexicanos) y 2) los resultados del Fondo de Atención a Migrantes (FAM). Se ilustra el funcionamiento de los programas con los testimonios de las personas entrevistadas. En el apartado final se sugiere una serie de políticas públicas.

\section{Metodología}

En la primera etapa, entre agosto y octubre de 2018, se realizaron entrevistas con funcionarios estatales, diputados, periodistas y miembros de las organizaciones de la sociedad civil. En la tabla 1 se indica a qué actores se entrevistaron y los objetivos de las entrevistas.

1 El proyecto fue financiado por la Comisión Nacional de Derechos Humanos. 
Tabla 1. Actores entrevistados

para el Proyecto Migración de Retorno en Nuevo León

\begin{tabular}{|c|c|c|}
\hline Entrevistados & Tipo de actor & Objetivo \\
\hline $\begin{array}{c}\text { Funcionarios de la Secretaría } \\
\text { General de Gobierno }\end{array}$ & $\begin{array}{c}\text { Gubernamental } \\
\text { (estatal) }\end{array}$ & $\begin{array}{l}\text { Conocer el funcionamiento } \\
\text { del FAM. }\end{array}$ \\
\hline $\begin{array}{l}\text { Funcionaria del Sistema } \\
\text { Nacional para el Desarrollo } \\
\text { Integral de la Familia (DIF) }\end{array}$ & $\begin{array}{l}\text { Gubernamental } \\
\text { (estatal) }\end{array}$ & $\begin{array}{c}\text { Conocer la labor del albergue } \\
\text { El Refugio para personas en } \\
\text { situación de calle y migrantes } \\
\text { en situación de retorno. }\end{array}$ \\
\hline $\begin{array}{l}\text { Diputado de la Comisión } \\
\text { de Asuntos Migratorios }\end{array}$ & $\begin{array}{c}\text { Poder Legislativo } \\
\text { (estatal) }\end{array}$ & $\begin{array}{l}\text { Conocer la iniciativa de Ley de } \\
\text { Migración en Nuevo León. }\end{array}$ \\
\hline $\begin{array}{c}\text { Funcionarias de la Secretaría } \\
\text { de Relaciones Exteriores }\end{array}$ & $\begin{array}{l}\text { Gubernamental } \\
\text { (federal) }\end{array}$ & $\begin{array}{c}\text { Conocer el funcionamiento } \\
\text { de Somos Mexicanos. }\end{array}$ \\
\hline $\begin{array}{l}\text { El director y la encargada } \\
\text { del albergue de migrantes }\end{array}$ & $\begin{array}{c}\text { No } \\
\text { gubernamental }\end{array}$ & $\begin{array}{l}\text { Conocer el tipo de apoyo } \\
\text { a la población de retorno. }\end{array}$ \\
\hline Periodista & $\begin{array}{c}\text { No } \\
\text { gubernamental }\end{array}$ & $\begin{array}{l}\text { Conocer la opinión de las } \\
\text { autoridades del estado sobre } \\
\text { el manejo del tema. }\end{array}$ \\
\hline
\end{tabular}

Fuente: elaboración propia con base en trabajo de campo (agosto-noviembre, 2018).

En la segunda etapa, de octubre a noviembre de 2018, se siguió la siguiente estrategia: para localizar a la población migrante de retorno en Nuevo León, se contactó a los albergues y a la dependencia de gobierno que canaliza el FAM, quienes proporcionaron algunos datos. De esta manera se ubicaron varias personas con diferentes perfiles y se conformó un grupo de foco con ellos en octubre de 2018. Esta actividad tuvo una duración de dos horas y media y se llevó a cabo en las instalaciones de El Colegio de la Frontera Norte. Se invitaron más personas, pero sólo tres acudieron al ejercicio.

La tabla 2 incluye la información de los participantes en el grupo de foco. El objeto de estudio fueron migrantes que tuvieron un retorno voluntario o forzoso, después de haber vivido varios años en Estados Unidos, y decidieron asentarse en la zona metropolitana de Monterrey (ZMM) porque eran originarios de la entidad y porque contaban con redes familiares en esa ciudad.

Los participantes, antes de integrar el grupo focal, llenaron una ficha de registro en la que incluían sus datos generales, el motivo del retorno y el tiempo de estancia en Estados Unidos. Después se inició la dinámica con los siguientes temas. 1) ¿Cómo se experimentó el proceso de retorno? Se preguntó sobre el proceso de ingreso a México y acerca de los trámites que realizaron para su reintegración en Nuevo León (actas de nacimiento, credencial del Instituto Nacional Electoral [INE]). 2) Tipo de ayuda que recibieron del Fondo de Apoyo a Migrantes y del gobierno estatal. Se abordaron los temas de capacitación, empleo, educación y salud. 3) Tópicos generales que les preocupaban. Cuando finalizó la actividad del grupo, se entrevistó a los participantes de forma breve 
e individual con el fin de ahondar en algunos puntos que quedaron pendientes en la dinámica del grupo. El audio se transcribió y se organizaron los temas en dos rubros: 1) proceso de ingreso y asentamiento en la ZMM y 2) beneficios del Fondo de Atención a Migrantes. La información se contrastó con la que se obtuvo por medio de los documentos oficiales y en entrevistas a los funcionarios.

Tabla 2. Características de la población entrevistada en Nuevo León

\begin{tabular}{|c|c|c|c|c|c|c|c|c|c|}
\hline Sexo & Edad & $\begin{array}{c}\text { Estado } \\
\text { civil }\end{array}$ & $\begin{array}{c}\text { Sitio } \\
\text { de } \\
\text { nacimiento }\end{array}$ & Educación & $\begin{array}{c}\text { Empleo } \\
\text { en Estados } \\
\text { Unidos }\end{array}$ & $\begin{array}{l}\text { Años en } \\
\text { Estados } \\
\text { Unidos }\end{array}$ & $\begin{array}{l}\text { Tipo de } \\
\text { retorno }\end{array}$ & $\begin{array}{c}\text { Familia } \\
\text { en Nuevo } \\
\text { León }\end{array}$ & $\begin{array}{c}\text { Tiempo } \\
\text { en Nuevo } \\
\text { León }\end{array}$ \\
\hline$F$ & 42 & $\begin{array}{l}\text { Soltera } \\
\text { sin hijos }\end{array}$ & $\begin{array}{l}\text { Nuevo } \\
\text { León }\end{array}$ & Técnica & Cuidadora & 8 & Voluntario & $\begin{array}{c}\text { Padres. } \\
\text { Sin familia } \\
\text { en Estados } \\
\text { Unidos. }\end{array}$ & $\begin{array}{c}1 \text { año, } 9 \\
\text { meses }\end{array}$ \\
\hline $\mathrm{M}$ & 45 & $\begin{array}{l}\text { Casado } \\
\text { con hijos }\end{array}$ & $\begin{array}{l}\text { Nuevo } \\
\text { León }\end{array}$ & Secundaria & $\begin{array}{c}\text { Pintor de } \\
\text { autos }\end{array}$ & 12 & Forzoso & $\begin{array}{c}\text { Hermanos. } \\
\text { La esposa } \\
\text { y los hijos } \\
\text { menores } \\
\text { regresaron } \\
\text { de forma } \\
\text { voluntaria } \\
\text { a México. }\end{array}$ & 1 año \\
\hline M & 26 & $\begin{array}{l}\text { Soltero } \\
\text { sin hijos }\end{array}$ & $\begin{array}{l}\text { Nuevo } \\
\text { León }\end{array}$ & Profesional & Estudiante & 25 & Forzoso & $\begin{array}{c}\text { Tíos. } \\
\text { Los padres } \\
\text { se } \\
\text { encuentran } \\
\text { en Estados } \\
\text { Unidos. }\end{array}$ & 1 año \\
\hline
\end{tabular}

Fuente: elaboración propia con base en trabajo de campo (agosto-noviembre, 2018).

\section{Discusión conceptual}

El glosario que elaboró la Organización Internacional para las Migraciones (OIM) define la migración de retorno como el "movimiento de personas que regresan a su país de origen o a su residencia habitual, generalmente después de haber pasado por lo menos un año en otro país. Este regreso puede ser voluntario o no. Incluye la repatriación voluntaria" (OIM, 2006, p. 39).

En México, Luciana Gandini, Fernando Lozano y Selene Gaspar (2015) elaboraron un estudio en torno al nuevo escenario de la migración México-Estados Unidos. Concluyen que el retorno debe verse como una parte del hecho migratorio en su totalidad y no como la conclusión de éste. Bajo esta consideración, se entiende que el migrante de retorno es "cualquier individuo que haya regresado a su lugar de origen, independientemente del tiempo de duración de la experiencia migratoria y del ciclo de vida en el cual ocurra, si regresa definitiva o temporalmente, voluntaria a forzadamente, después de haber tenido una experiencia migratoria internacional” (p. 33). 
En un texto de corte sociológico, Tovar Cuevas y Victoria Paredes (2013) analizan la relación entre el retorno y el emprendimiento, y concluyen que no hay una definición única de migrante en situación de retorno. Dicha investigación resume las posturas teóricas más importantes sobre este concepto y resulta útil para el conocimiento de algunas tipologías generadas por los especialistas.

Entre éstas, una que ha sido muy utilizada en México es la propuesta de Jorge Durand (2004), ya que su construcción deriva de sus investigaciones sobre el tema. Otra tipología es la que propone Mestries (2013), quien considera que, ante la dificultad de agrupar los motivos del retorno, es mejor diferenciar los factores objetivos de los subjetivos. Entre los primeros, se encuentran 1) los ligados al migrante y 2) los ligados al entorno. En el segundo se ubican 1) el capital humano, 2) el capital social, 3) la identidad comunitaria, 4) el proyecto migratorio, 5) las circunstancias afectivas familiares y 6) los elementos de atracción hacia el pueblo de origen.

La otra dimensión que aparece en este tema es la jurídica. Con el objetivo de aclarar los términos que se utilizan aquí, se ha tomado de base el texto de Calva y Alarcón (2018). De acuerdo con dichos autores, para fines legales y como resultado de las políticas antimigrantes de los recientes gobiernos en Estados Unidos, el Department of Homeland Security (DHS) distingue dos tipos de deportaciones: remoción y retorno. La remoción (removal) es la expulsión de los extranjeros con base en una orden formal de deportación y tiene consecuencias administrativas o penales. Incluye el impedimento de regresar a Estados Unidos por varios años. El retorno (return) es la expulsión de los extranjeros que no se fundamenta en una orden formal de deportación y que no tiene consecuencias administrativas ni penales (p. 48).

Los autores aseveran que la autoridad mexicana (Unidad de Política Migratoria) usa el término "repatriación" para referirse a los mexicanos que son forzados a regresar, sobre todo de Estados Unidos. Más adelante aparece otro término, "devueltos", que utiliza la Encuesta Norte sobre Migración (EMIF), de El Colegio de la Frontera Norte (COLEF). Debido a que numerosos migrantes habían sido devueltos varias veces, la EMIF norte utiliza el término "evento" para esos casos en lugar de deportación (Calva y Alarcón, 2018, p. 49).

Para finalizar esta discusión, se retoma el trabajo de la OIM. Este organismo define la deportación como "acto del Estado en el ejercicio de su soberanía mediante el cual envía a un extranjero fuera de su territorio a otro lugar, después de rechazar su admisión o de habérsele terminado el permiso de permanecer en dicho Estado". También se alude a la expulsión como "un acto de autoridad del Estado con la intención y el efecto de asegurar la salida del territorio de ese Estado de una o varias personas (extranjeros) contra su voluntad" (OIM, 2006, pp. 16-25).

En el informe del proyecto que fue la base de este documento, se considera que la población migrante de retorno es el "conjunto de personas que nacieron en México, residían o intentaron residir en Estados Unidos y regresaron a su país. Esta definición incluye tanto a las personas que intentaron cruzar hacia Estados Unidos, como a aquellas que regresaron después de pasar años fuera, 
ya sea en forma obligatoria o voluntaria" (COLEF y Comisión Nacional de los Derechos Humanos [CNDH], 2019, p. 14).

Otro tema a definir es la reinserción, que es un proceso posterior a la migración de retorno. Ésta se refiere a la integración y adaptación a la sociedad receptora y tiene que ver con los aspectos culturales, legales, institucionales, educativos y laborales. Existen varias definiciones del concepto de las cuales se toma la de Ortiz (2015), quien se refiere a la reintegración social como

un proceso multifactorial en el que intervienen aspectos estructurales, como las condiciones del mercado laboral (oportunidades reales de empleo, salarios y prestaciones laborales), el acceso a los sistemas sociales de protección (seguridad social, Instituto del Fondo Nacional de la Vivienda para los Trabajadores [INFONAVIT], Administradora de Fondos para el Retiro [AFORE]) y el ingreso al sistema educativo; factores microestructurales como la situación familiar o la posesión de una red social afianzada, y aspectos psicoemocionales como el sentimiento de empatía por el lugar de origen o la disposición de reestablecerse en la sociedad. (p. 221)

Aunque aquí se coincide con esa definición, para los fines del presente artículo se utiliza como sinónimo la palabra reinserción porque así quedó asentado en el proyecto original. Lo anterior se relaciona con el tema de las políticas públicas del gobierno mexicano para facilitar este proceso y que serán señaladas en el siguiente apartado.

\section{Política pública y retorno en México}

No es objetivo de este apartado revisar todo el proceso de las políticas públicas, sino presentar algunos elementos que permitan observar el surgimiento de las políticas sobre el retorno de migrantes a México. Las preguntas son: ¿los agentes gubernamentales perciben este fenómeno que tanto ha estudiado la academia como un problema público? y ¿qué acciones se han diseñado al respecto? He aquí algunas definiciones básicas de políticas públicas.

De acuerdo con la definición de Aguilar (2012), el autor que más ha trabajado el tema en México, se entiende por política pública el

1) Conjunto de acciones intencionales y causales [...].

2) Conjunto de acciones cuya intencionalidad y causalidad han sido definidas por el tipo de interlocución que tiene lugar entre el gobierno y sectores de la ciudadanía.

3) Conjunto de acciones a emprender que han sido decididas por las autoridades públicas legítimas y cuya decisión las convierte formalmente en públicas y legítimas.

4) Conjunto de acciones que son llevadas a cabo por actores gubernamentales o por éstos en asociación con actores sociales (económicos, civiles). 
5) Conjunto de acciones que configuran un patrón de comportamiento del gobierno y de la sociedad. (p. 29)

Para Aguilar (2012), lo específico y peculiar de la política pública consiste en ser un conjunto de acciones intencionales y causales, orientadas a la realización de un objetivo de interés o beneficio público, cuyos lineamientos de acción, agentes, instrumentos, procedimientos y recursos se reproducen en el tiempo de manera constante y coherente.

De estas definiciones se rescata el interés en un problema público como punto de partida y el sostenimiento en el tiempo como características de esta clase de disposiciones.

Sobre el mecanismo de hechura de la política pública se alude a que:

la política pública recoge las demandas de los sectores civiles y políticos, las reelabora en objetivos y acciones legalmente compatibles, aprovecha la información y el conocimiento que existen en una sociedad para seleccionar las acciones y las formas de organización capaces de producir los objetivos decididos, e incluye el cálculo de los recursos públicos que las acciones necesitan para operar y alcanzar los resultados esperados. Alrededor de la política pública se enlazan leyes, poderes públicos, actores políticos y sociales, recursos financieros y procesos administrativos. (Aguilar, 2012, p. 30)

Uno de los aspectos más importantes a considerar es que la política pública es la respuesta a una situación considerada socialmente inaceptable, es decir, que responde a un problema público.

Por otra parte, Cejudo y Michel (2016) analizan el tema de la coherencia de las políticas públicas en su diseño, en su implementación y en su relación con otras políticas que tienen finalidades similares:

Existe una amplia variedad de políticas que son efectivas, que cumplen con sus objetivos y que atienden adecuadamente a sus destinatarios, pero que, al valorarlas desde una perspectiva más amplia, son redundantes, realizan las mismas acciones que otras políticas, persiguen más o menos los mismos objetivos y en ningún caso queda claro cuál es el objetivo amplio al que buscan contribuir ni en qué medida lo harán. (p. 5)

En el Informe especial: políticas multinivel para el retorno y la (re)inserción de migrantes mexicanos y sus familias de El COLEF y la Comisión Nacional de Derechos Humanos (CNDH) (2019) se alude a una política pública en materia de retorno centrada en dos instrumentos: la Ley de Migración (2011) publicada durante el sexenio de Felipe Calderón y el Programa Especial de Migración (2014-2018) (Secretaría de Gobernación [SEGOB], 2014) creado en el gobierno de Enrique Peña Nieto. Sobre esas bases aparecen la estrategia Somos Mexicanos y el FAM. No obstante, ni la Ley de Migración ni la Ley General de Población ni ninguna normatividad específica permiten identificar las perspectivas institucionales de ordenamiento y de atención del Estado mexicano en materia 
de migración de retorno. La normatividad federal no ofrece claridad conceptual acerca de los distintos grupos que participan en los procesos de retorno. Se parte de una definición muy general en la que se concibe a los migrantes que han retornado como un grupo homogéneo, con las mismas necesidades de atención. La política focalizada en la recepción (estrategia Somos Mexicanos) visibiliza la vulnerabilidad de las personas que han retornado en el contexto a donde llegan, pero no contribuye a dar una visión a mediano y largo plazos de la migración internacional en México.

El proceso de reinserción inicia cuando el migrante llega al lugar donde ha decidido radicar y se enfrenta a los obstáculos legales y burocráticos que debe superar, aunque las experiencias son diferentes en cada entidad. El caso de Nuevo León es el que se abordará en este trabajo y puede constituir un ejemplo de la escasa atención a un problema que tiene una política federal limitada que en el plano local no se traduce en instrumentos suficientes para la atención de la población afectada.

\section{El estado de la cuestión}

Cuando en México la migración de retorno empezó a convertirse en problema, los análisis se realizaron en diferentes contextos y con distintos objetivos. Aquí se comentan algunas investigaciones y se destaca lo poco que se ha escrito sobre la política pública que concierne al tema y la atención a las necesidades de la población de retorno.

En 2010 se publicó el trabajo de Moreno (2010) en torno a una práctica exitosa para la población migrante en Mexicali, Baja California. Se trata de uno de los pocos textos sobre la política pública de atención a este sector, el cual ya formaba una población importante en ese año.

En 2013 aparece el documento de Mestries (2013), que indaga sobre un tema relativamente nuevo en los estudios migratorios. El estudio de caso lo realiza en Veracruz y el objetivo fue analizar las condiciones de reintegración laboral en este medio rural.

Rivera (2013) analiza el retorno como resultado de la articulación y de la dinámica de mercados de trabajos globales. El escenario es el municipio de Nezahualcóyotl y se entrevista a hombres migrantes que retornaron a México. En esta misma línea, el investigador escribe en 2015 sobre las espacialidades múltiples de la ciudad. Su trabajo se propone "analizar las implicaciones vitales y societales del retorno migratorio y la inserción social y laboral en contextos urbanos en México" (Rivera, 2015, p. 243). Además, discute el recurso metodológico de las narrativas para ilustrar los circuitos migratorios.

En 2018 hallamos los trabajos de Cruz Islas (2018) sobre el estado de Hidalgo y el de Ramírez (2018) sobre Tabasco. El primero es un estudio demográfico de la migración de retorno en municipios de Hidalgo. Y el segundo analiza la reinserción laboral de los migrantes que retornan a Tabasco. 
El libro de Meza (2017), Emigración, tránsito y retorno en México, aborda en algunos de sus capítulos la situación de la migración de retorno. De un total de ocho apartados, tres se dedican a ello en la Ciudad de México, Jalisco y Puebla. Estudia el retorno y el proceso de inserción laboral de los migrantes en la Ciudad de México.

Joanna Foote Williams (2017) examina el fenómeno de la recepción de migrantes en cinco comunidades rurales de Jalisco y Puebla. Y, en esa misma publicación, Corona, Jiménez y Guerra (2017) estudian la migración de retorno en Puebla.

El tema de la niñez migrante merece atención aparte por tratarse de una población con características muy específicas. El libro de Zúñiga y Giorguli (2019), Niñas y niños en la migración de Estados Unidos a México: la generación 0.5, investiga el caso de los menores de edad que llegaron a México procedentes de Estados Unidos desde principios del siglo XXI.

El trabajo que coordinaron Levine, Núñez y Verea (2015), Nuevas experiencias de la migración de retorno, observa varias facetas de la migración de retorno. Comprende 14 capítulos que abordan temas diversos, desde la política internacional hasta los estudios de caso.

Destaca el trabajo de Peláez y París (2016) sobre las mujeres deportadas que llegan a Tijuana. Sierra, González y Rosales (2016) se enfocan en la salud como motivo del retorno. Moctezuma y Martínez (2015) hablan del retorno de migrantes en Michoacán (p. 135). El caso de la sierra norte de Puebla lo tratan D’Aubeterre y Riveramar (2016). Cruz Manjarrez (2016) se refiere al transnacionalismo y al retorno en una comunidad zapoteca. Se trata de trabajos en distintos contextos urbanos y rurales y con objetivos diversos que no sólo aluden a casos en concreto, sino también a temas transversales, como la salud.

También se distingue el caso de la Universidad Autónoma de Sinaloa, porque tiene una amplia producción bibliográfica sobre la migración de retorno. Dos libros analizan el tema en una entidad que no se encuentra en las regiones tradicionales de la migración. En el que se publicó en 2015, Migración de retorno en América Latina, una visión multidisciplinaria, coordinado por Erika Montoya y Miriam Nava, se abordan los temas teóricos de la construcción social de la identidad migrante (Ibarra y Ceballos, 2015) y las interpretaciones teóricas sobre el retorno (Herrera y Montoya, 2015). Destacan los estudios de caso en varias ciudades de México: Valenzuela y Medina (2015, p. 151) analizan el tema de los jóvenes migrantes de retorno que se insertan en el mercado laboral de Sinaloa como profesores de inglés. Otro de los apartados relevantes de este libro es el que escribió Ortiz (2015) sobre las familias retornadas y su reintegración a la zona metropolitana de Guadalajara (ZMG). Entre los aportes notorios de su investigación, están la ubicación territorial en una gran zona metropolitana y la discusión conceptual del significado de reintegración.

El más reciente texto de Rivera (2020), ¿Volver a casa? Migrantes de retorno en América Latina. Debates, tendencias y experiencias divergentes, es una compilación de trabajos que aborda diversas facetas de la migración de 
retorno. En el amplio y bien documentado capítulo introductorio se analizan de forma exhaustiva los estudios sobre migración de retorno y deportaciones. El libro se divide en varias secciones: "I. Tendencias y perfiles contemporáneos"; “II. De regreso a México"; "III. De vuelta a Centroamérica”; y "IV. Circulación y regreso a Sudamérica”. A diferencia de otras compilaciones, ésta es muy amplia e incluye trabajos ubicados en otras zonas de América. Del caso mexicano, se abordan la reinserción laboral de los deportados en Tijuana, las familias mixtecas fracturadas por las deportaciones, la indigencia en una ciudad fronteriza del norte de México, las mujeres que retornaron a la ZMG y la reinserción sociocultural de los migrantes que retornaron a la región mazahua en el Estado de México.

El libro De regreso al terruño. Estrategias de reinserción educativa y laboral de familias migrantes de retorno y menores binacionales de Herrera y Montoya (2020), es un análisis de la migración de retorno en el estado de Sinaloa. Parte de la consideración de "que las familias migrantes de retorno poseen capital humano y financiero y recurren a las redes sociales para generar actividades laborales" (p. 8). El estudio se realizó en la ciudad de Culiacán, se utilizó una metodología mixta y constituye una interesante revisión del factor familiar en los procesos de migración y reinserción.

Como se observa, es muy amplia la producción de trabajos en torno a la migración de retorno en México. En ellos prevalecen los análisis sobre reinserción laboral y educativa, los aspectos subjetivos del retorno y algunas propuestas de política pública. Con respecto a las entidades donde se ubican los estudios, predominan Puebla, Jalisco, Michoacán, Tijuana, Sinaloa y el Estado de México. Se localizaron dos textos sobre la ZMG. Se puede afirmar que sobre los temas de política pública, hay pocos estudios. Los de Moreno (2010) y los de Cruz (2018) ofrecen algunas propuestas, pero no se encontraron análisis centrados en el tema.

\section{Migración de retorno a México y a Nuevo León}

Antes de entrar en el estudio de caso de Nuevo León y con el fin de proporcionar datos objetivos sobre el retorno de migrantes a México, se presentan a continuación algunas cifras.

El análisis de Orranca y Calva (2019) es la base de la información que se presenta aquí. En él se indica que en el quinquenio 2005-2010 retornaron 824000 personas, y entre 2010 y 2015 fueron 443 000; es decir, hubo un descenso de $46 \%$. Con respecto al perfil presentado, en el primer periodo se ubican sobre todo hombres en edad laboral. Se trata de una población que regresa a México con necesidades básicas, como comida, un sitio donde vivir, empleo y, en el caso de los niños, niñas y adolescentes, una escuela en la cual continuar su formación. Por la cantidad de personas, es un fenómeno que tiene un fuerte impacto sobre las poblaciones mexicanas. 
En cuanto a las entidades donde se asientan estas personas, el estudio indica que por lo general se ubican en la denominada "región tradicional de la migración”: Aguascalientes, Colima, Durango, Guanajuato, Jalisco, Michoacán, Nayarit, San Luis Potosí y Zacatecas (Orranca y Calva, 2019, p. 20).

Nuevo León no está considerada como una entidad expulsora. Tampoco tiene una frontera receptora de migrantes debido a la carencia de poblaciones contiguas al condado de Laredo, Texas, con el cual limita. La importancia de estudiar este caso radica en que la ZMM es el centro urbano más importante de la región noreste, lo cual significa que las personas que retornan a través de Tamaulipas y Coahuila, tienden a moverse a Monterrey en busca de oportunidades o para vivir en sus comunidades de origen.

En la tabla 3 se presentan los retornos de mexicanos entre 2016 y 2019. Durante este periodo, 4 de cada 10 se hicieron por los estados de Coahuila y Tamaulipas, entidades contiguas a Nuevo León.

Tabla 3. Retorno de mexicanos entre 2016 y 2019

\begin{tabular}{|l|r|c|c|c|}
\hline Entidad federativa y punto de recepción & \multicolumn{1}{|c|}{2016} & \multicolumn{1}{c|}{2017} & \multicolumn{1}{c|}{2018} & \multicolumn{1}{c|}{2019} \\
\hline Baja California & 63975 & 47264 & 62485 & 66170 \\
\hline Chihuahua & 12066 & 5802 & 16114 & 26131 \\
\hline Coahuila & 33708 & 16763 & 11884 & 12449 \\
\hline Sonora & 37994 & 29634 & 35537 & 35274 \\
\hline Tamaulipas & 57322 & 48377 & 69452 & 71102 \\
\hline Ciudad de México & 14840 & 19224 & 8197 & 132 \\
\hline Total de eventos de repatriación & 219905 & 167064 & 203669 & 211258 \\
\hline
\end{tabular}

Fuente: elaboración propia con datos de la Unidad de Política Migratoria (SEGOB, 2018a, 2018b, 2019 y 2020).

Con respecto al número de personas nacidas en Nuevo León que han retornado durante el periodo 2016-2019, la proporción es cerca de 1\% del total nacional, que es un porcentaje bajo en comparación con otras entidades. Lo que llama la atención en este caso es la ubicación territorial de Monterrey: lugar estratégico para los migrantes que retornan a sus lugares de origen (véase tabla 4).

El otro hecho que hace de la ZMM un sitio importante para la población que retorna por Coahuila y Tamaulipas, es la violencia en la frontera noreste. En la práctica, para huir de las ciudades fronterizas de Tamaulipas (Nuevo Laredo, Reynosa y Matamoros), las personas viajan de inmediato a Nuevo León, donde se asientan un tiempo en lo que regresan a sus sitios de origen o deciden quedarse ahí si encuentran alguna fuente de empleo. 


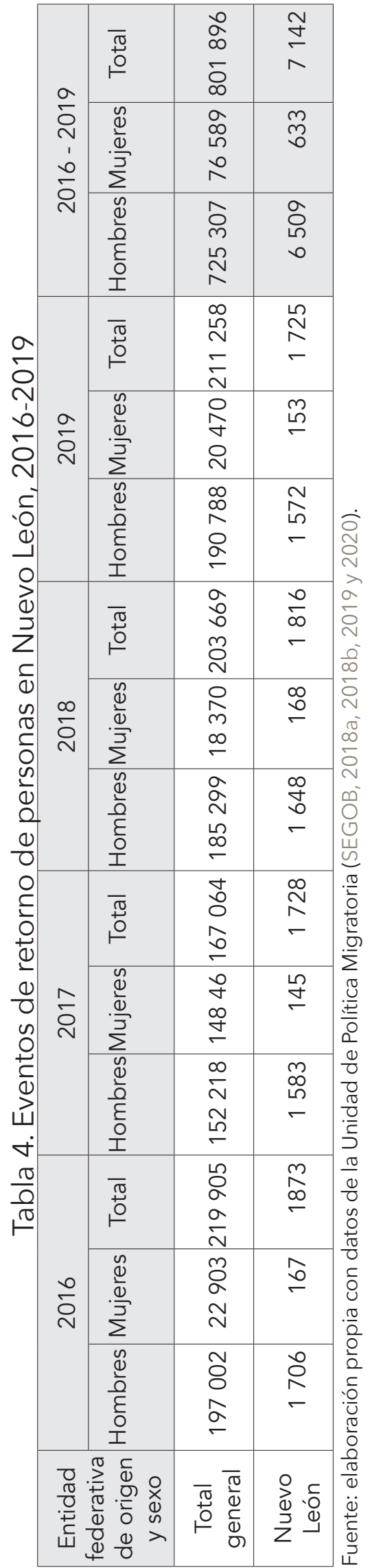




\section{Contexto estatal y urbano de Nuevo León}

El estado de Nuevo León se ubica en la zona noreste de México. Limita al norte con Estados Unidos; al este, con Tamaulipas; al sur, con San Luis Potosí; al oeste, con Coahuila y Zacatecas. Posee un punto de cruce a Estados Unidos en el municipio de Anáhuac a través del puente Colombia-Solidaridad. De acuerdo con el Instituto Nacional de Estadística y Geografía (INEGI), Nuevo León ocupa el séptimo lugar nacional por número de habitantes, con una población de 5784442 personas. No obstante, según el más reciente censo (INEGI, 2020), la ZMM, que está conformada por 18 municipios, es la segunda zona nacional más poblada, con 5343171 habitantes.

Figura 1. Principales ciudades fronterizas del noreste de México

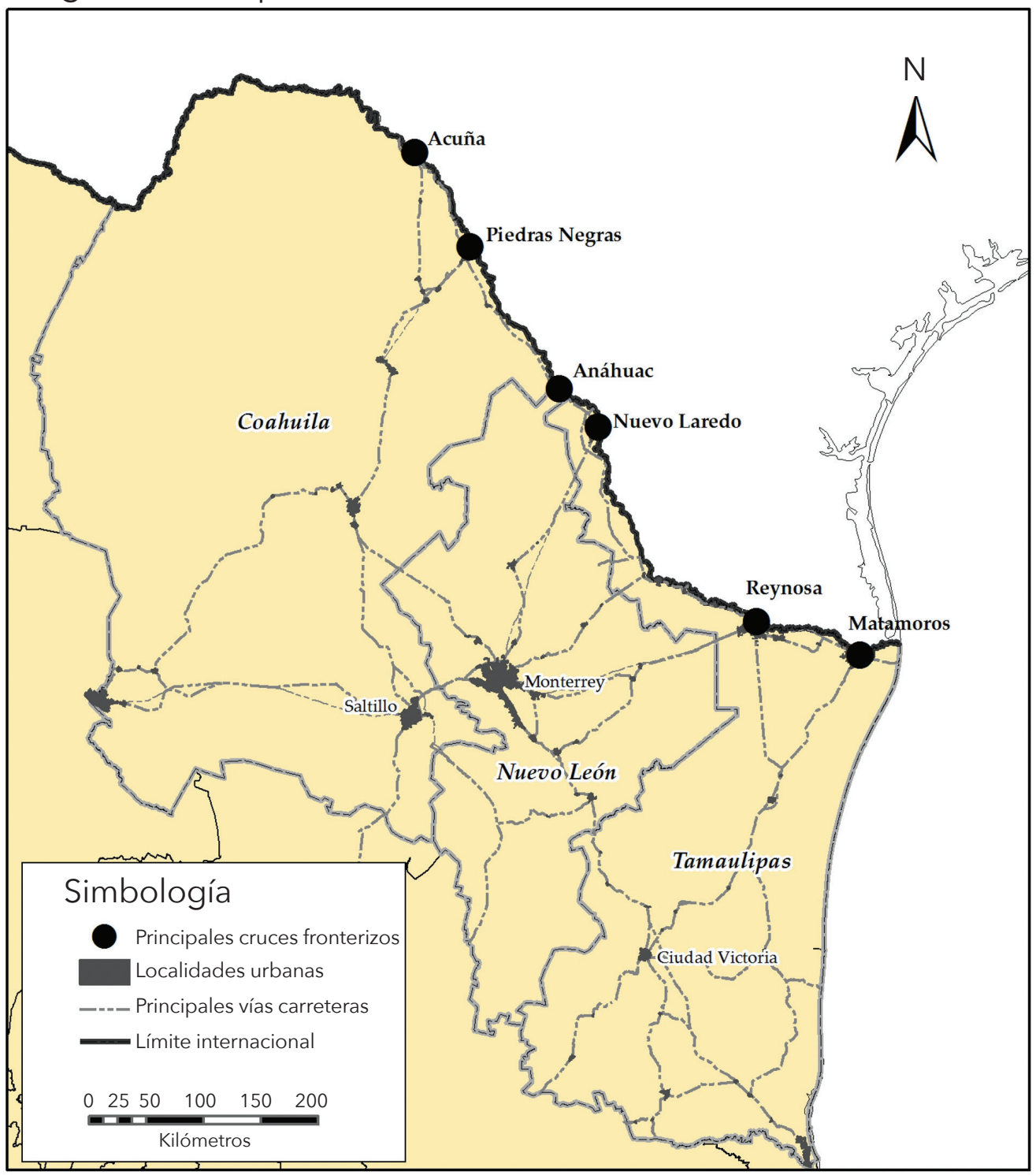

Fuente: elaboración de Gustavo A. Vázquez con base en datos del INEGI (2010). 
Por su ubicación, en la ZMM convergen varios flujos migratorios internos e internacionales: 1) de tránsito hacia Estados Unidos (la mayoría son centroamericanos); 2) los solicitantes de visas laborales H2A cuyo trámite se realiza en el consulado de Estados Unidos en Nuevo León; 3) la población que regresa por Coahuila y Tamaulipas, originaria de diversos estados de México; 4) las personas refugiadas o solicitantes de refugio que ha reubicado la Oficina del Alto Comisionado de las Naciones Unidas para los Refugiados (ACNUR); 5) se debe destacar también que se trata de una entidad que por su dinámica económica atrae a la población de diversas entidades. ${ }^{2}$

La frontera noreste de México tiene cinco puntos donde se realizan los retornos: Ciudad Acuña y Piedras Negras (Coahuila) y Nuevo Laredo, Reynosa y Matamoros (Tamaulipas). Los migrantes que regresan tienen la opción de quedarse en dichas ciudades pero, ante el riesgo que esto significa, una cantidad no determinada se traslada a Monterrey para asentarse ahí y luego moverse a sus lugares de origen. La figura 1 muestra la movilidad en esta zona.

\section{Política pública y el proceso de retorno}

En su momento, el primer apoyo a esta población fue la estrategia Somos Mexicanos, iniciativa de la SEGOB instrumentada por el Instituto Nacional de Migración (INM) a partir del 26 de marzo de 2014. Consistía en que los mexicanos provenientes de Estados Unidos ingresaban a México a través de los módulos del INM donde se les proporcionaban varios servicios: alimentación, orientación en salud, identidad (constancia de repatriación y la clave única de registro de población [CURP]), comunicación (llamadas telefónicas), traslado local y apoyo para transporte foráneo, albergue (en caso de ser necesario), opciones laborales y acceso a programas sociales. A esta estrategia después se unieron los consulados de México en Estados Unidos, que daban atención para el retorno voluntario, protección consular y orientación a familiares de repatriados (funcionaria de la Secretaría de Relaciones Exteriores, comunicación personal, septiembre de 2018).

Durante el sexenio que inició en 2018, ha funcionado el Programa de Repatriación con un enfoque parecido al de Somos Mexicanos (Gobierno de México, 2021). No obstante, el 24 de junio de 2021 las secretarías de Gobernación y de Relaciones Exteriores anunciaron un nuevo programa de apoyo para la educación, la salud y el desarrollo económico de los migrantes retornados. Esta nueva estrategia incluye 35 aliados gubernamentales y consiste de 42 acciones de apoyo (Gobierno de México, 2021a).

2 De acuerdo con Bedoya-Rangel, Jáuregui, Ávila y Picazzo (2018), en 2015 residían en Nuevo León 1032567 personas nacidas en otra entidad federativa, lo que representa $20.6 \%$ del total de la población; es decir, una de cada cinco personas son inmigrantes. De los migrantes recientes (que en 2010 vivían en otra entidad), 50\% proviene de entidades vecinas, como San Luis Potosí, Tamaulipas, Coahuila y Zacatecas. El resto se traslada de otras entidades, como Ciudad de México, Hidalgo, Estado de México y Veracruz (p. 141). 
No obstante las buenas intenciones de esa estrategia, en las entrevistas se da a conocer que debido al alto número de personas que regresan y por los horarios en los que se realizan estos procedimientos, no había a menudo suficiente personal del INM. También sucedía que a las personas que acababan de retornar, las subían a unos autobuses, que a veces custodiaban las policías estatales de Tamaulipas y Nuevo León, para llevarlas a Monterrey. Es en esa ciudad donde ellas inician los trámites migratorios.

El primer obstáculo que encuentran los recién llegados, es que los trámites de apoyo a la población de retorno se llevan a cabo sólo a través de instancias de los gobiernos estatal o federal, cuyas oficinas se localizan en el municipio de Monterrey. Para una persona que desconoce la ciudad, resulta muy complicado desplazarse. Además, el sistema de transporte es ineficiente y tiene un costo elevado. La figura 2 muestra la ZMM. En el recuadro con color más claro se indica la zona centro, a la cual llegan los autobuses provenientes de la frontera.

Figura 2. Zona Metropolitana de Monterrey

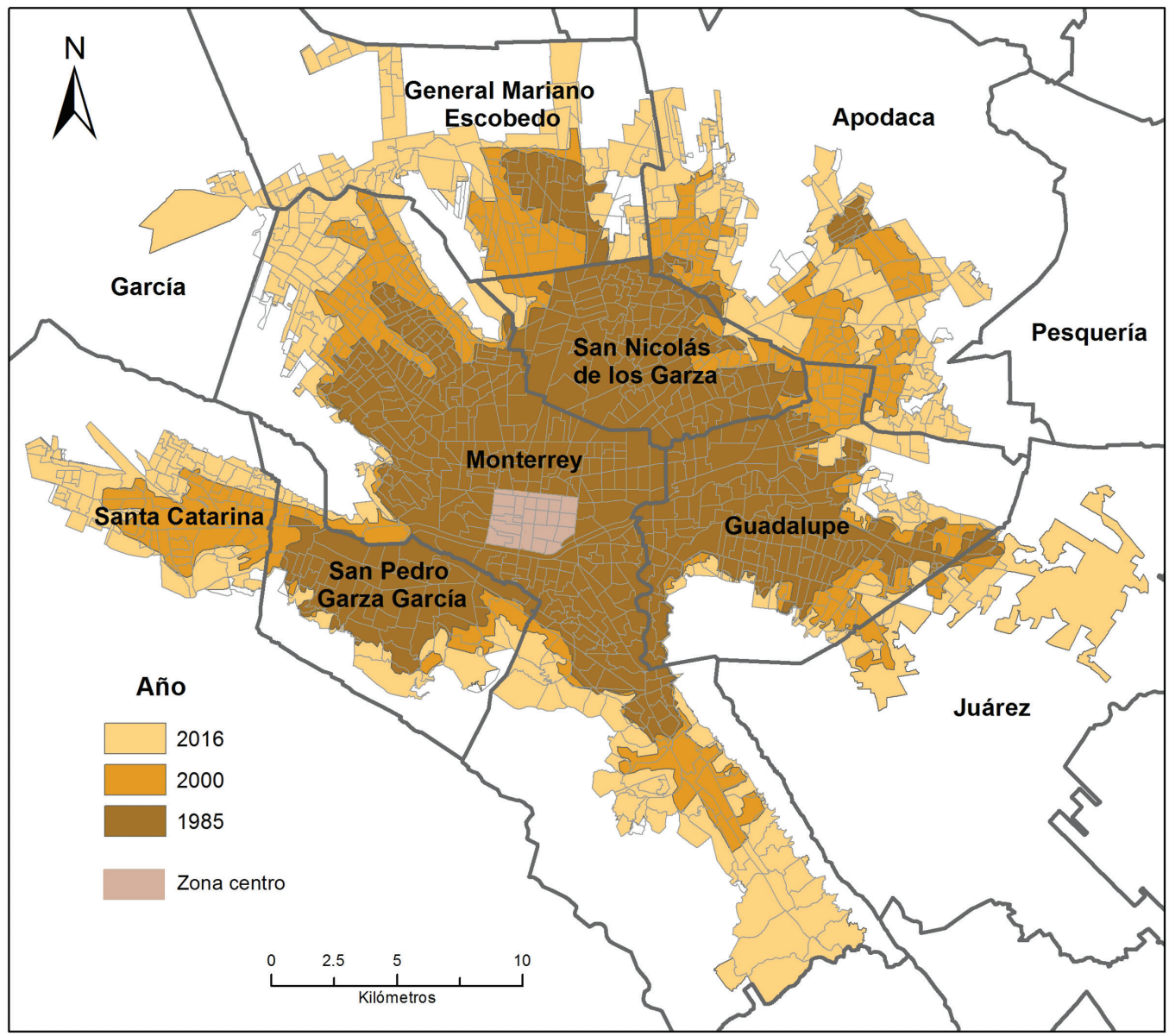

Fuente: elaboración de Gustavo A. Vázquez con base en datos del INEGI (2015). 
El proceso de regreso inicia cuando la autoridad estadounidense entrega a la persona a su par en México y cruza el puente fronterizo en Coahuila o Tamaulipas. Una vez ingresada a territorio nacional, en el módulo de atención a migrantes (una oficina pequeña) se le ofrece agua, algo de comer y ayuda limitada para el transporte. También se le brinda información sobre los servicios de salud, la ubicación de los albergues en la ciudad y que se puede tener acceso a otro tipo de apoyo para retornados en su estado de origen. No obstante, a quienes se entrevistó, no se les comunicó en qué oficinas se podían hacer estas gestiones y se les sugirió que acudieran al Instituto Nacional de Migración, donde se les notificarían los programas existentes (Fondo de Apoyo a Migrantes [FAM]).

Los beneficiarios del FAM en Nuevo León debían conocer su existencia, pero las personas entrevistadas comentaron que la información les llegó a través de los compañeros y no por un medio oficial. La ruta oficial de información debía ser que un agente del INM informa al migrante sobre el FAM y lo remite a la Secretaría General de Gobierno del Estado de Nuevo León, que es la responsable de gestionar y dar seguimiento a todas las solicitudes de reingreso hasta que se emite el cheque de apoyo. En torno a este proceso, las personas entrevistadas afirman:

Me sentía desamparada. No sabía con quién acercarme. (Mujer) Sólo cumplen con recibirte y llevarte. No te saben dar la ayuda como debe ser. (Mujer)

Uno viene y se asusta, aunque hayas nacido aquí, aunque aparentes conocer. (Hombre)

Con los comentarios anteriores se concluye que si bien hubo atención al problema público, ésta fue parcial, y las autoridades realizaron sólo las acciones asistenciales y momentáneas que se describen. Es decir, que la estrategia Somos Mexicanos tuvo procesos administrativos limitados y no fomentó la creación de leyes para estos casos. Tampoco nadie la evaluó y, por lo tanto, no cumplía con las características de una política pública (Aguilar, 2012, p. 30). Más bien se trató de una acción coyuntural, derivada de la emergencia del momento.

\section{La migración y el gobierno en Nuevo León}

A pesar de la gran cantidad de flujos migratorios que convergen en la ZMM, en Nuevo León no hay una instancia que reconozca a la población migrante que transita por el estado. En el caso de la migración irregular, la atención se da a través de las casas y albergues para migrantes que dirigen los religiosos y la sociedad civil, quienes a veces atienden a la población que regresa al país.

La Secretaría General de Gobierno de Nuevo León ha considerado el tema de la migración. Esa dependencia tiene el objetivo de "conducir los asuntos internos del orden político del estado, coordinando las relaciones del ejecutivo con el gobierno federal, los otros poderes del estado, los municipios de la enti- 
dad, así como agentes consulares". La Subsecretaría General de Gobierno es la institución que observa el tema de forma directa.

Durante los sexenios de Natividad González Parás (2003-2009) y Rodrigo Medina (2009-2015) se creó la Dirección de Relaciones Federales, Consulares y de Atención al Migrante, entidad dependiente de la Subsecretaría General de Gobierno. Pero la dependencia desapareció y hasta la fecha el gobierno de Nuevo León no ha creado ningún área similar.

El Plan Estratégico Nuevo León 2030, publicado en 2021, hace escasa referencia a la migración en la entidad, sólo apunta la migración interna y el tema de la discriminación, y no hay líneas ni estrategias específicas para la atención a ese problema, lo que da idea de la limitada importancia que tiene en la entidad (Consejo Nuevo León, 2021, p. 215).

En Nuevo León ha habido tres iniciativas de una Ley de Atención a Migrantes. La primera en 2014, la segunda en 2016 y la tercera en 2018. Todas consideran incluir en la agenda estatal el tema migratorio, en especial las migraciones en tránsito y en situación irregular, pero no han contemplado la de retorno como un asunto que deba legislarse en la entidad. Además, el hecho de que esté considerado en la agenda no significa que haya pasado a la siguiente fase. No se ha hecho durante tres legislaturas distintas, lo que demuestra que el tema no es prioritario para el gobierno.

En entrevista con un diputado de la Comisión de Asuntos Migratorios, comentó que "con la llegada de Donald Trump a la presidencia de Estados Unidos se pensó que el estado se iba a invadir de migrantes deportados y por eso se creó una Comisión Especial de Asuntos Migratorios". No obstante, ésta sesionó sólo tres veces y, aunque estaba vigente en el momento de este estudio, en la práctica no ha funcionado. Existe la percepción de que "los migrantes se quedan aquí en tránsito y los migrantes que llegan a Coahuila se están viniendo a Nuevo León" (Comunicación personal, diputado de la Comisión Asuntos Migratorios, agosto, 2018).

Es decir, en Nuevo León, a pesar de las evidencias que han documentado algunas investigaciones y las cifras que han publicado algunos organismos (ACNUR, albergues y casas para migrantes) sobre la presencia de población migrante retornada, en tránsito o refugiada, no se percibe que esta situación sea un problema público que deba atenderse (Aguilar, 2012). En consecuencia, no se han creado las instancias de gobierno que se dediquen al tema, y menos aún, leyes, disposiciones o presupuesto específico.

En el ámbito federal se instauró como una política de atención a la migración de retorno, el Fondo de Apoyo a Migrantes. No obstante, la operación fue acatada por los gobiernos estatales beneficiados, quienes la implementaron de manera diferenciada. El hecho de que Nuevo León no perciba que la migración sea un problema público, ocasiona que no haya instancias especializadas para la canalización de dicho fondo, a diferencia de Puebla, Michoacán o Tamaulipas, donde sí hay una política pública local: leyes, poderes públicos, actores políticos y sociales, recursos financieros y procesos administrativos (Aguilar, 2012), lo que ha facilitado la aplicación del FAM y su seguimiento. 


\section{Programas de apoyo a los migrantes en Nuevo León}

En 2009 surge el FAM dentro del marco del Ramo 23, Provisiones Salariales y Económicas, del Proyecto de Egresos de la Federación. El programa que funcionó hasta 2018 cedía a cada entidad la forma de aplicación. El FAM contemplaba varias acciones susceptibles de apoyo: capacitación, actividades que fomenten el autoempleo, bono individual de hasta treinta mil pesos, apoyo a la familia y los grupos, operación de albergues que atienden a los migrantes de retorno y pasaje terrestre para regresar a su lugar de origen, cuyo monto máximo era de dos mil pesos (Diario Oficial de la Federación, 2018). En el caso de la capacitación y el apoyo al autoempleo, cada gobierno estatal estableció sus políticas. El presente documento se centra en las acciones del gobierno estatal de Nuevo León.

El FAM se basó en la Ley General de Migración y en el Programa Especial de Migración (2014-2018), y respondió al problema público de la necesidad de reinserción de la población migrante que retornaba a México. Se trató de un "conjunto de acciones intencionales y causales, con un interés y beneficio público" (Aguilar, 2012). De acuerdo con la conceptualización de política pública, contó con una serie de acciones (beneficios económicos), instrumentos (reglas de operación), agentes (autoridades estatales), procedimientos (señalados en las reglas de operación) y recursos (presupuestos anuales), todos ellos componentes de una política pública. Sin embargo, no se reprodujo de manera constante y coherente, duró pocos años y no fue evaluado.

Las reglas de operación del programa establecieron en 2018 para Nuevo León 2482124 de pesos, cifra muy inferior a los 26 millones que recibió Tamaulipas ese mismo año que, aunque el estado tiene frontera con Estados Unidos, no hay retorno por ese sitio.

Como ya se mencionó, la Subsecretaría General de Gobierno de Nuevo León es la que ha atendido a las personas migrantes de retorno. Hay una oficina de atención ciudadana y una persona encargada de gestionar los 30 mil pesos (alrededor de 1200 dólares estadounidenses) de apoyo económico para los migrantes retornados.

El encargado del programa afirma que "éste no se anuncia en medios para evitar que lleguen miles de gentes. Ya que hay líderes que les piden hasta el 20\% por la gestión" (Comunicación personal, Subsecretaría de Gobierno, agosto de 2018).

Los requisitos que el gobierno de Nuevo León estableció para que las personas se inscribieran en el programa y recibieran los 30 mil pesos son a) contar con el documento que compruebe su deportación, b) presentar un plan de trabajo y c) comprobar su residencia (si no la tenían, se les canalizaba a los albergues).

Para el acceso a los programas es necesario comprobar el retorno mediante la hoja de repatriación. De no tenerla, el proceso puede resultar lento, complicado y costoso para la persona migrante, pues cuando ésta no obtiene su hoja de repatriación en el momento del cruce, tiene que iniciar el proceso en Monterrey. 
Las personas entrevistadas narran que los autobuses que vienen de la frontera llegan a la central de autobuses, ubicada en el centro de la ciudad. Ahí la persona decide si se queda o busca un medio de transporte para su ciudad de origen. Si decide permanecer y tiene familiares en la ciudad, se traslada con ellos; si no, sólo hay un albergue que brinda apoyo a los mexicanos. Pertenece al DIF y permite la estancia por un máximo de tres noches, pero durante el día se pide a los huéspedes que abandonen las instalaciones. Son pocas las personas que pueden pagar otro hospedaje.

La copia de la hoja de repatriación se obtiene en el INM, que está al sur de la ciudad, a casi 10 kilómetros del centro. Para llegar, es necesario buscar y pagar un medio de transporte. En las instalaciones del instituto hay que recorrer varias oficinas para localizar a la única persona que se encarga del trámite. Una vez que se recibe la atención, el migrante debe demostrar que está retornando, lo que no es tan sencillo. Lo más común es que los familiares y los amigos de las personas envíen los documentos que acreditan su estancia en Estados Unidos. Una vez demostrada ésta, se puede obtener la constancia, cuyo trámite lleva varias semanas. Cabe señalar que ese documento es indispensable para tener acceso a los apoyos estatales.

A pesar de la gran cantidad de personas oriundas que han retornado (véase tabla 4), es muy baja la proporción de éstas que se benefician del FAM. La instancia responsable del programa proporcionó los siguientes datos sobre los apoyos otorgados entre 2016 y 2018:

a) Hubo convenio con el Instituto de Capacitación y Educación para el Trabajo (ICET).

b) El apoyo individual de 30 mil pesos está dirigido a fomentar el autoempleo.

En ese lapso se entregaron 93 apoyos, equivalentes a 2640000 de pesos.

- En 2016, 10

- En 2017, 33

- En 2018, 50

- A mujeres, 28

- A hombres, 65

c) Se dio apoyo a dos albergues:

- A El Refugio (DIF) se otorgaron 450000 pesos.

- Nuevo Corazón de Jesús, Asociación Civil recibió 150000 pesos. (Gobierno del Estado, 2018, comunicación interna).

Cabe señalar que en la operación del FAM de 2009 a 2018 el Consejo Nacional de Evaluación de la Política de Desarrollo Social (CONEVAL) no lo evaluó ni a escala federal ni a escala local en Nuevo León, por lo que no hay indicadores del impacto en la población atendida. El gobierno estatal no da seguimiento a las personas beneficiadas. En consecuencia, se desconoce la forma en que se ha empleado el recurso. 
De acuerdo con los testimonios que se recabaron, el monto que otorga el FAM tarda en llegar, es insuficiente y tiende a usarse para resolver las necesidades económicas básicas.

El ICET, una institución de larga tradición, da los cursos de capacitación. Los talleres se imparten en diferentes sedes y están dispersos por varios municipios de la ZMM, en su página oficial, el ICET reporta más de trescientos cursos en catorce planteles en el estado, lo cual dificulta que una persona se traslade a donde se imparte el de su interés.

El diseño de los cursos en poco se ajusta a las necesidades de las personas que retornan, ya sea por sus habilidades, niveles educativos, edad o sexo. Son talleres genéricos para la población desocupada cuyo nivel educativo es básico, y además responden a la oferta laboral específica de la entidad (básicamente industrial). Del mismo modo, $90 \%$ de los cursos se dirigen a la población masculina. En contraste, los cursos para mujeres están vinculados a los imaginarios de género, relacionados con la belleza y la costura.

Además, los empleadores explotan las habilidades productivas y tienden a dar bajas remuneraciones, sobre todo en el caso de las mujeres. Una de las entrevistadas, bilingüe y con estudios profesionales, dijo que el sueldo era "tan poco", que no le alcanzaba ni para los traslados. Por eso optó por el autoempleo: puso un local comercial de abarrotes en una habitación de su casa.

La edad representa un impedimento para el ingreso en el mercado laboral. La larga permanencia en Estados Unidos hace que las habilidades laborales de las personas resulten poco aplicables a las de la sociedad de recepción. Por ejemplo, en el caso de uno de los entrevistados, en Estados Unidos se dedicaba a polarizar vidrios de autos, actividad que está prohibida en Nuevo León y por lo tanto debía buscar un trabajo nuevo. Ya sea por el conocimiento diferenciado o por ser mayor de 35 años, resulta que no es posible obtener empleo. Por lo tanto, la única opción es el autoempleo. Los entrevistados afirman que "aquí [en México] las oportunidades se acaban por la edad; no pasamos de trabajo de paquetería en Soriana. En Estados Unidos no hay discriminación por la edad" (Comunicación personal, hombre adulto, septiembre de 2018).

Con respecto a la salud, el único apoyo que se les daba, era a través del Seguro Popular (mecanismo que estuvo vigente hasta el 31 de diciembre de 2018). Para recibirlo, la persona debía realizar los trámites en una oficina que también estaba centralizada. El Seguro Popular era un derecho que va más allá de la situación migratoria de la persona y se aplica a todos los mexicanos que no gozan de la seguridad social, con independencia de su condición. Por lo tanto, no se trata de un beneficio pensado para satisfacer las necesidades específicas de una población de retorno.

En resumen, las autoridades de Nuevo León adaptaron el FAM a las condiciones y a la cultura laboral de la entidad. No se diseñaron nuevas acciones para la población de retorno ni para sus necesidades de empleo, educación o salud. Tampoco hubo una política pública específica para dichos migrantes, como se observó en el trabajo de campo de este proyecto de investigación. Es necesario entablar una discusión más amplia que derive en la creación de leyes y poderes públicos, procedimientos y recursos que reconozcan que la migración es un tema de interés público en Nuevo León. 


\section{Propuesta de política pública}

Entre las demandas de las personas retornadas, destacan:

1. La creación de una oficina integral de migración, con atención permanente a las personas, que dependa del gobierno de Nuevo León y que apoye la reinserción social y laboral.

2. Un servicio médico que incluya el cuidado de la salud mental, pues los retornados se sienten muy afectados.

3. Dar información y seguimiento a los proyectos productivos que ellos proponen.

4. Mayor involucramiento de los gobiernos municipales, pues en la práctica no proporcionan ningún apoyo.

Con las consideraciones de las personas entrevistadas, se arriba a una propuesta de política pública en favor de la migración de retorno que debe considerar, en principio:

1. La difusión a través de los consulados del proceso de retorno, de los apoyos e informar a dónde acudir en el estado de origen o en el de destino.

2. Que se garantice que la información se dé y alcance a todas las personas retornadas a través de los módulos de atención fronteriza.

3. El diseño de una página web específica (\#soyretornado) que informe sobre los apoyos existentes en cada estado y la forma de acceso a ellos.

4. La creación de una Dirección de Migración u oficina de atención a migrantes estatal y de un módulo especial para atender a los migrantes en las cabeceras municipales y cuyo objetivo sea brindar información acerca de los programas y que oriente sobre la forma de realizar las gestiones.

5. Dada la diversidad de situaciones que se ha comentado en este documento, es preciso diseñar programas más amplios de atención a migrantes en retorno.

6. Facilitar apoyos para la gestión de créditos financieros para vivienda y automóvil.

7. Que la Secretaría del Trabajo y Previsión Social proponga vincular los saberes de los retornados con las empresas.

8. Incluir a las personas retornadas en la responsabilidad social empresarial.

9. Atender la diversidad de situaciones de las personas migrantes de retorno, considerando sus capacidades y necesidades diferenciadas.

10. Ante la falta de acciones del gobierno estatal, es necesario que la academia y la sociedad civil se reúnan con el sector gubernamental para proporcionar datos y sensibilizarlo sobre la importancia que tiene la ZMM para la migración interna e internacional.

Lo anterior no será posible sin una normativa que obligue a llevar a cabo estos procesos. Es decir, que la discusión a fondo del problema lleve a la formulación de una política pública. 
Es necesario subrayar que tanto la estrategia de Somos Mexicanos como el Fondo de Apoyo a Migrantes dejaron de funcionar con el gobierno federal que inició el 1 de diciembre de 2018. En estos últimos años no se han conocido iniciativas semejantes, por lo cual es posible que las situaciones aquí presentadas se hayan vuelto aún más complejas.

\section{Reflexiones finales}

Este artículo presenta un análisis de los actores gubernamentales que intervienen en el proceso de retorno en el estado de Nuevo León. Se partió de la identificación de las políticas públicas federales que se implementan en la entidad para detectar su efecto en la población que retorna a ella, con lo cual se enriquece la discusión en torno al proceso de reinserción.

El trabajo de campo constató la carencia de una política pública local de atención a la población migrante y que las autoridades nuevoleonesas no perciben el tema como problema público y que, por lo tanto, no hay normativa ni diseño de instituciones para atenderlo. Lo que contrasta con lo que se observa en Puebla, que tiene el Proyecto de Desarrollo Integral y Reinserción de Migrantes Poblanos cuya gama de asistencia para la población retornada es amplia. En Michoacán se ha puesto en funcionamiento el programa novedoso de acceso al seguro social estadounidense para los migrantes michoacanos. Tamaulipas instauró el Instituto Tamaulipeco para los Migrantes, donde se atiende el tema. Que en Nuevo León no se reconozca el problema como público tiene un efecto en la atención a la población que vive el proceso de retorno y reinserción.

Si bien el tema del retorno ha producido una buena cantidad de bibliografía, hay varias limitantes:

1) Pocos textos sobre las entidades que están fuera del circuito migratorio tradicional. La mayoría de los trabajos revisados se refieren a Puebla, Jalisco, Michoacán, Baja California y Estado de México. Una excepción son los trabajos sobre Sinaloa (Montoya y Nava, 2015; Herrera y Montoya, 2020).

2) Los temas que tratan el retorno y la reinserción son diversos, pero se concentran en las variables económicas, los contrastes culturales, las subjetividades y el empleo. No hay investigación sobre las políticas públicas existentes ni sobre la aplicación que de ellas hacen las autoridades locales.

3) El proceso de reinserción se analiza sin considerar el marco de las políticas públicas que se han creado para el tema.

Lo anterior demuestra la falta de estudios sobre la importancia de las ciudades o de las zonas metropolitanas no fronterizas como ejes en los que giran diferentes flujos migratorios. Hay estudios sobre la Ciudad de México, el Estado de México y Guadalajara, pero no sobre Nuevo León, Coahuila o Tamaulipas.

Otra línea de investigación necesaria son las políticas públicas de atención a la migración de retorno. De la literatura revisada, dos artículos se ocupan del tema, uno de 2010 relacionado con Mexicali y otro de 2018 referente a Hidalgo. 
Cárdenas y Alaminos (2020) analizan las iniciativas y los programas del gobierno federal mexicano dirigidos a la población retornada. Se trata de un trabajo muy amplio que estudia la estrategia de Somos Mexicanos y el FAM. Ahí se establece el marco general de análisis de esa política pública. Pero no se encontraron estudios de caso locales sobre la aplicación del FAM.

Nuevo León no registra la migración irregular que transita por el estado ni las personas retornadas de Estados Unidos que se asientan en Monterrey; tampoco las personas refugiadas o solicitantes de asilo, excepto las que contabiliza la ACNUR.

El presente artículo da visibilidad a la migración de retorno y subraya, a través de un estudio de caso, las insuficiencias de la política pública al respecto. Sin duda, la limitante más grande fue la dificultad de acceso a la población retornada y las pocas entrevistas que se pudieron realizar, lo cual se debió a la falta de registros oficiales. Esto se relaciona con la carencia de una institución especializada en el tema. Por eso habrá que diseñar un método para tener acceso a estas personas. Las entrevistas que se realizaron para esta investigación constituyen un ejemplo de las dificultades que experimentan las personas en los procesos de retorno y de reinserción.

Queda pendiente el análisis de la información que brinde un mayor número de personas con diferentes perfiles y que se dé seguimiento a su proceso de reintegración a más largo plazo.

\section{Agradecimientos}

Las autoras agradecen la colaboración del geógrafo Gustavo Vázquez, técnico académico de El Colegio de la Frontera Norte por la búsqueda y el procesamiento de información.

\section{Referencias}

Aguilar, L. F. (2012). Política pública. México: Siglo XXI Editores.

Bedoya, Y., Jáuregui, J. A., Ávila, M. J., y Picazzo, E. (2018). Tendencias recientes de la migración interna en Nuevo León, México. Espacio I+D Innovación más Desarrollo, 7(18), 131-146. doi: https://doi.org/10.31644/ IMASD.7.2018.a07

Calva, L. E., y Alarcón, R. (2018). Migrantes mexicanos deportados y sus planes para reingresar a Estados Unidos al inicio del gobierno de Donald Trump. Revista Mexicana de Ciencias Políticas y Sociales, 63(233), 43-68. Recuperado de http://www.scielo.org.mx/scielo.php?script=sci_arttext\&pi$\mathrm{d}=$ S0185-19182018000200043

Cámara de Diputados. (1974). Ley General de Población. Diario Oficial de la Federación, 7 de enero, última reforma 12 de julio de 2018. Recuperado de Ley General de Población (diputados.gob.mx) 
Cámara de Diputados. (2011). Ley de Migración. Diario Oficial de la Federación, 25 de mayo, última reforma 20 de mayo de 2021. Recuperado de Ley de Migración (diputados.gob.mx)

Cejudo, G. M., y Michel, C. L. (2016). Coherencia y políticas públicas. Metas, instrumentos y poblaciones objetivo. Gestión y Política Pública, 25(1), 3-31. Recuperado de v25n1a1.pdf (scielo.org.mx)

Consejo Nuevo León. (2021). Plan estratégico 2030, Nuevo León Mañana. Recuperado de Consejo Nuevo León | Plan Estratégico (conl.mx)

Corona Jiménez, M. Á., y Guerra, M. A. de A. (2017). La migración de retorno. El gran reto de la segunda década del siglo XXI. Un estudio regional en Puebla. En L. Meza González, C. Pederzini Villareal y M. S. de la Peña Padilla (coords.), Emigración, tránsito y retorno en México (pp. 183-216). Guadalajara: Instituto Tecnológico y de Estudios Superiores de Occidente (ITESO).

Cruz Islas, C. (2018). Políticas públicas y migración de retorno desde Estados Unidos: el caso de los municipios metropolitanos hidalguenses, TLA-Melaua. Revista de Ciencias Sociales, 12(45), 208-238. Recuperado de http://www. scielo.org.mx/scielo.php?script=sci_arttext\&pid=S1870-69162018000200209

Cruz Manjarrez, A. (2016). Transnacionalismo y migración de retorno en una comunidad zapoteca. En E. Levine, S. Núñez y M. Verea (coords.), Nuevas experiencias de la migración de retorno (pp. 205-226). México: Universidad Autónoma de México (UNAM).

D’Aubeterre, M., y Riveramar, M. (2016). Migración de retorno en la sierra Norte de Puebla a raíz de la crisis económica estadunidense. En E. Levine, S. Núñez y M. Verea (coords.), Nuevas experiencias de la migración de retorno (pp. 159-180). México: UNAM.

Diario Oficial de la Federación. (21 de marzo de 2018). Lineamientos de operación del Fondo de Apoyo a Migrantes. Secretaría de Gobernación. Recuperado de http://www.dof.gob.mx/nota_detalle.php?codigo=5516826\&fecha $=21 / 03 / 2018$

Durand, J. (2004). Ensayo teórico sobre la migración de retorno. El principio de rendimiento decreciente. Cuadernos Geográficos, 35(2), 103-116. Recuperado de https: / / revistaseug.ugr.es/index.php/cuadgeo/article/view/1784

El Colegio de la Frontera Norte (COLEF) y Comisión Nacional de Derechos Humanos (CNDH). (2019). Informe especial: política multinivel para el retorno y la (re)inserción de migrantes mexicanos y sus familias. Tijuana: CNDH. Recuperado de Políticas multinivel para el retorno y la (re) inserción de migrantes mexicanos y sus familias | El Colegio de la Frontera Norte (colef.mx)

Foote W., J. (2017). Familiaridad, hostilidad y hospitalidad: recepción de migrantes de retorno en Jalisco y Puebla. En L. Meza González, C. Pederzini Villareal y M. S. de la Peña Padilla (coords.), Emigración, tránsito y retorno en México (pp. 149-182). Guadalajara: ITESO.

Gandini, L., Lozano, F., y Gaspar, S. (2015). El retorno en el nuevo escenario de la migración entre México y Estados Unidos. México: Consejo Nacional de Población (CONAPO). Recuperado de https: / /www.gob.mx/cms/uploads/ attachment/file/39174/ElRetornoEnelNuevoEscenariodeMigracion.pdf 
Gobierno de México. (2021). Programa de repatriación. Recuperado de Programa de Repatriación | Instituto Nacional de Migración | Gobierno | gob.mx (www.gob.mx)

Gobierno de México. (2021a). Familias mexicanas migrantes en retorno y repatriadas tienen nuevas opciones de apoyo en educación, salud y desarrollo económico. Recuperado de Familias mexicanas migrantes en retorno y repatriadas tiene nuevas opciones de apoyo en educación, salud y desarrollo económico | Secretaría de Relaciones Exteriores | Gobierno | gob.mx (www. gob.mx)

Herrera, M., y Montoya, E. (2015). Migración de retorno: una interpretación teórica y conceptual frente a las cifras de migrantes retornados de Estados Unidos a México. En E. Montoya Zavala y M. Nava Zazueta (coords.), Migración de retorno en América Latina. Una visión multidisciplinaria (pp. 75108). Culiacán: UAS.

Herrera, M., y Montoya, E. (2020). De regreso al terruño: estrategias de reinserción educativa y laboral de familias migrantes de retorno menores binacionales. Culiacán: Artificios Universidad y Universidad Autónoma de Sinaloa (UAS).

Ibarra, G., y Ceballos, T. (2015). Ilusión del retorno y construcción social de la identidad del migrante. En E. Montoya Zavala y M. Nava Zazueta (coords.), Migración de retorno en América Latina. Una visión multidisciplinaria (pp. 21-52). Culiacán: UAS.

Levine, E., Núñez, S., y Verea, M. (coords.). (2016). Nuevas experiencias de la migración de retorno. México: UNAM.

Mestries, F. (2013). Los migrantes de retorno ante un futuro incierto. Sociológica, 28(78), 171-212. Recuperado de http://www.scielo.org.mx/scielo. php?script=sci_arttext\&pid=S0187-01732013000100006

Meza González, L. (2017). Migrantes retornados en la Ciudad de México: es más fácil irse que regresar. En L. Meza González, C. Pederzini Villareal y M. de la Peña Padilla (coords.), Emigración, tránsito y retorno a México (pp. 117148). Guadalajara: ITESO.

Moctezuma, M. , y Martínez, D. (2016). El retorno de migrantes mexicanos, con acento en Michoacán. En E. Levine, S. Núñez y M. Verea (coords.), Nuevas experiencias de la migración de retorno (pp.136-158). México: UNAM.

Montoya, E., y Nava, M. (coords.). (2015). Migración de retorno en América Latina. Una visión multidisciplinaria. Culiacán: UAS.

Moreno, J. (2010). Proceso de gestión pública innovadora: el caso de los módulos de atención a migrantes en Baja California. Estudios Fronterizos, 11(21), 143-170. Recuperado de http://www.scielo.org.mx/scielo.php?script=sci_ arttext\&pid=S0187-69612010000100005

Organización Internacional para las Migraciones (OIM). (2006). Organización Internacional para las Migraciones. Recuperado de https://publications.iom. int/system/files/pdf/iml_7_sp.pdf

Ortiz R., M. (2015). Familias retornadas de Estados Unidos y su reintegración a la zona metropolitana de Guadalajara. En E. Montoya Zavala y M. Nava 
Zazueta (coords.), Migración de retorno en América Latina. Una visión multidisciplinaria (pp. 209-243). Culiacán: UAS.

Peláez, D., y París, D. (2016). Deportación femenina y separación familiar: experiencias de mexicanas deportadas a Tijuana. En E. Levine, S. Núñez y M. Verea (coords.), Nuevas experiencias de la migración de retorno (pp. 59-80). México: UNAM.

Orranca Romano, P., y Calva Sánchez, L. (2019). Dimensión y caracterización de la migración de retorno México-Estados Unidos 2000-2017. En COLEF y CNDH, Informe especial: política multnivel para el retorno y la (re)inserción de migrantes mexicanos y sus familias (pp.17-60). Tijuana: CNDH. Recuperado de Políticas multinivel para el retorno y la (re) inserción de migrantes mexicanos y sus familias | El Colegio de la Frontera Norte (www.colef.mx)

Ramírez, G. (2018). La reinserción sociocultural y laboral de los migrantes de retorno en Tabasco. Revista Iberoamericana de Producción Académica y Gestión Educativa,5(10). Recuperado de https://pag.org.mx/index.php/PAG/ article/viewFile/769/1101

Rivera S., L. (2013). Reinserción social y laboral de inmigrantes retornados de Estados Unidos en un contexto urbano, Iztapalapa. Revista de Ciencias Sociales y Humanidades (75), 29-56. Recuperado de https: / / www. redalyc.org / pdf/393/39348329003.pdf

Rivera S., L. (2015). Narrativas de retorno y movilidad. Entre prácticas de involucramiento y espacialidades múltiples de la ciudad. Estudios Políticos, Colombia (47), 243-264. Recuperado de https://www.redalyc.org/ pdf/164/16440055014.pdf

Rivera S., L. (ed.). (2020). ¿Volver a casa? Migrantes de retorno en América Latina. Debates, tendencias y experiencias divergentes. Ciudad de México: El Colegio de México.

Secretaría de Gobernación (SEGOB). (2018a). Gobierno de México. Recuperado de http://portales.segob.gob.mx/es/PoliticaMigratoria/CuadrosBOLETIN?Anual=2016\&Secc $=5$

Secretaría de Gobernación (SEGOB). (2018b). Gobierno de México. Recuperado de http://portales.segob.gob.mx/es/PoliticaMigratoria/CuadrosBOLETIN?Anual=2017\&Secc=5

Secretaría de Gobernación (SEGOB). (2019). Gobierno de México. Recuperado de http://portales.segob.gob.mx/es/PoliticaMigratoria/CuadrosBOLETIN?Anual=2018\&Secc=5

Secretaría de Gobernación (SEGOB). (2020). Eventos de repatriación de mexicanos desde Estados Unidos, según entidad federativa y punto de recepción, 2019. Recuperado de http://portales.segob.gob.mx/es/PoliticaMigratoria/ CuadrosBOLETIN?Anual=2019\&Secc $=5$

Secretaría de Gobernación, Instituto Nacional de Migración. (2014). Programa Especial de Migración 2014-2018. Diario Oficial de la Federación, 30 de abril. Recuperado de Programa Especial de Migración (PEM) 2014-2018 | Instituto Nacional de Migración | Gobierno | gob.mx (www.gob.mx)

Sierra, L. de la, González, M., y Rosales, Y. (2016). La salud como motivo de retorno de migrantes a México. En E. Levine, S. Núñez y M. Verea (coords.), 
Nuevas experiencias de la migración de retorno. México (pp. 119-134). México: UNAM.

Tovar, L., y Victoria, M. (2013). Migración de retorno y emprendimiento. Revisión de literatura. Revista de Economía Institucional, 15(29), 41-65. Recuperado de http://www.scielo.org.co/scielo.php?script=sci_abstract\&pi$\mathrm{d}=$ S0124-59962013000200004

Valenzuela, B., y Medina, A. (2015). Jóvenes migrantes de retorno e incorporación al mercado de trabajo. El caso de los profesores de inglés en Sinaloa. En E. Montoya y M. Nava (coords.), Migración de retorno en América Latina. Una visión multidisciplinaria (pp. 151-180). Culiacán: UAS.

Zúñiga, V., y Giorguli, S. (2019). Niñas y niños en la migración de Estados Unidos a México: la generación 0.5. Ciudad de México: El Colegio de México. 